\title{
BMJ Open Safety and availability of clofazimine in the treatment of multidrug and extensively drug-resistant tuberculosis: analysis of published guidance and meta-analysis of cohort studies
}

\author{
Thomas J Hwang, ${ }^{1,2}$ Svetlana Dotsenko, ${ }^{1}$ Azizkhon Jafarov, ${ }^{3}$ Karin Weyer, ${ }^{3}$ \\ Dennis Falzon, ${ }^{3}$ Kaspars Lunte, ${ }^{4}$ Paul Nunn, ${ }^{5}$ Ernesto Jaramillo, ${ }^{3}$ \\ Salmaan Keshavjee, ${ }^{6}$ Douglas F Wares ${ }^{3}$
}

To cite: Hwang TJ,

Dotsenko S, Jafarov A, et al. Safety and availability of clofazimine in the treatment of multidrug and extensively drug-resistant tuberculosis: analysis of published guidance and meta-analysis of cohort studies. BMJ Open 2014:4:e004143.

doi:10.1136/bmjopen-2013004143

- Prepublication history and additional material for this paper is available online. To view these files please visit the journal online (http://dx.doi.org/10.1136/ bmjopen-2013-004143).

SK and DFW contributed equally towards the article.

Received 30 September 2013 Revised 20 November 2013 Accepted 22 November 2013

\section{CrossMark}

For numbered affiliations see end of article.

Correspondence to

Thomas J Hwang;

tjhwang@college.harvard.edu

\section{ABSTRACT}

Objectives: Given the spread of multidrug-resistant tuberculosis (MDR-TB), new therapies are urgently needed, including the repurposing of existing drugs. We aimed to assess key considerations for the clinical and programmatic use of clofazimine (Cfz), a riminophenazine with antimycobacterial activity currently used to treat leprosy.

Design: Fixed and random effects meta-analysis of cohort studies and systematic review.

Setting: Electronic and manual searches were combined.

Inclusion criteria: Observational studies on treatment of multidrug-resistant and extremely drug-resistant tuberculosis with Cfz or a $\mathrm{Cfz}$-containing regimen, and published guidance and documents relating to cost and availability were eligible.

Results: 5 observational studies enrolled 861 patients, of which 602 received Cfz. The pooled proportion of adverse drug reactions requiring discontinuation of $\mathrm{Cfz}$ treatment was $0.1 \%(95 \%$ $\mathrm{Cl}(0.0$ to $0.6 \%))$, and the median frequency of all adverse events was $5.1 \%$. Cfz showed in vitro efficacy against Mycobacterium tuberculosis, and $\mathrm{Cfz}$-containing regimens may have had a useful role in the treatment of patients with drug-resistant strains and who had limited alternative treatment options. However, Cfz uptake remains insufficient to meet global needs; there is only one internationally quality-assured manufacturer, which produces a limited quantity of the drug prioritised for treatment of leprosy, the only indication for which the drug is registered.

Conclusions: While the data were limited, Cfz was associated with a risk for adverse drug reactions comparable to that of first-line TB treatment, which could be reasonably managed under programmatic conditions. However, low market availability and high cost are important barriers to access to $\mathrm{Cfz}$ for patients with MDR-TB.

\section{Strengths and limitations of this study}

- We have reviewed a comprehensive body of peer-reviewed literature and policy guidance relating to the safety, use, cost and availability of clofazimine $(\mathrm{Cfz})$ in clinical practice.

- This study shows that the burden of safety issues associated with $\mathrm{Cfz}$ use appears to be manageable by national TB programmes. The widespread use of $\mathrm{Cfz}$ is limited by low availability and relatively high cost.

- Few studies were included in the meta-analysis since only a smaller number of studies have been conducted with $\mathrm{Cfz}$. Further research is needed.

\section{INTRODUCTION}

Drug-resistant strains of tuberculosis (TB) pose a serious obstacle to progress in global TB control. ${ }^{1}$ In 2011, there were an estimated half a million new cases of multidrug-resistant tuberculosis (MDR-TB; resistance to, at least, rifampicin and isoniazid) worldwide. ${ }^{2}$ Extensively drug-resistant (XDR-TB) cases, a form of MDR-TB with additional resistance to any fluoroquinolone and an injectable second-line drug, have been identified in 84 countries. $^{2}{ }^{3} \mathrm{~A}$ recent survey from Belarus reported that nearly one in two of all enrolled TB patients had MDR-TB, the highest proportion of MDR ever recorded. ${ }^{4}$

The recent approval of bedaquiline by the US Food and Drug Administration (FDA), the first drug developed for TB treatment in nearly a half-century and the filing of delamanid with the European Medicines Agency (EMA), are promising developments for the treatment of TB. ${ }^{5}{ }^{6}$ However, the management 
of drug-resistant strains of Mycobacterium tuberculosis ( $M$ tb) necessitates new effective treatment regimens, composed of at least four effective drugs. In light of the limited treatment options available for patients affected by severe patterns of drug-resistant $\mathrm{TB}$, some have recommended repurposing older drugs, though there are significant concerns with the adverse drug reaction (ADR) profiles and long-term safety of several agents and conflicting evidence of their efficacy. ${ }^{78}$ One potential candidate to be repurposed is clofazimine (Cfz), a riminophenazine derived from an R-substitution at the imino group. ${ }^{9} \mathrm{Cfz}$ has apparent antimycobacterial and anti-inflammatory activity, though its precise mechanism of action is still unclear. ${ }^{10}$ The drug is known to be highly lipophilic, accumulating in fatty tissues with uptake by human mononuclear phagocytes, the same cells infected by $M t b .{ }^{11} \mathrm{Cfz}$ also appears to exhibit a property uniquely relevant for tuberculosis treatment: despite its long half-life and accumulation in tissue, the risk of developing resistance is relatively low. ${ }^{12}$

Although Cfz was originally developed for the treatment of tuberculosis, its current medical indication is for the treatment of multibacillary and paucibacillary leprosy, including severe erythema nodosum leprosum reactions in patients with leprosy. ${ }^{13}$ While in vitro studies suggested high anti-TB activity, poor in vivo results in the mid-1950s led to the abandonment of clinical development as an antituberculosis agent. ${ }^{14}{ }^{15}$ In the past decade, there has been renewed and growing interest in the use of Cfz as an anti-TB agent. An MDR-TB treatment observational study conducted in Bangladesh showed favourable outcomes, even with a significantly shorter treatment duration than the current WHO recommended regimen. ${ }^{16}$ A multicountry randomised control trial to evaluate a standardised 9-month regimen containing Cfz for the treatment of MDR-TB is currently under way, and observational cohort studies are being conducted in some West African countries. ${ }^{17}$ Given the growing evidence supporting the use of Cfz in the treatment of patients with MDR-TB and XDR-TB treatment, we sought to assess the key considerations, including safety, effectiveness, management and cost, in relation to the programmatic and clinical use of Cfz by national TB programmes (NTP).

\section{METHODS}

\section{Study design and data sources}

Our meta-analysis and systematic review were conducted using a prospective protocol according to MOOSE (Meta-analysis of Observational Studies in Epidemiology) and PRISMA (Preferred Reporting Items for Systematic Reviews and Meta-analyses) guidelines for reporting systematic reviews of observational study results (see online supplementary material). ${ }^{18}{ }^{19}$ Studies published between 1950 and May 2013 were identified from an electronic search of the PubMed, MEDLINE, Embase and Cochrane Library databases. The key words and Medical
Subject Heading terms included: 'clofazimine', 'B663', lamprene', 'tuberculosis', 'side effects', 'adverse events', 'adverse drug reactions', 'sequella', 'toxicity', 'tolerability', 'outcomes', 'treatment', 'effectiveness', 'efficacy', 'cure', 'success', 'guideline', 'treatment' or 'safety'. We contacted researchers and manually collected references of all retrieved articles, selected review articles, clinical trial registration notices and conference abstracts, as needed. These additional studies were merged with our search results, following exclusion of non-relevant or duplicate citations. Policy guidelines and drug label information were retrieved from manual searches of WHO publications, as well as those of two stringent regulatory agencies, the US FDA and EMA.

\section{Outcome variables and data extraction}

The aim of our study was to perform a meta-analysis of the safety of Cfz from published studies and a systematic analysis of the effectiveness, management and cost of Cfz from the peer-reviewed literature as well as published guidance.

For our safety analysis, our primary outcomes of interest were adverse events and ADR. We defined an ADR as an appreciably harmful or unpleasant reaction caused by a drug that is serious enough to warrant the discontinuation or revision of treatment. ${ }^{20}$ In contrast, an adverse event included any undesirable reactions reported by patients or clinicians, including mild reactions that had no bearing on treatment. Since the use of the term 'adverse event' and 'serious adverse events' was inconsistent in the reviewed studies and the criteria for judging an adverse event as serious were not consistently reported, we used ADR as a measure of Cfz's safety profile. Using methods described previously, ${ }^{21}$ we used challenge-dechallenge to evaluate ADR data: a reaction was attributed solely to $\mathrm{Cfz}$ if discontinuation of the drug or reducing the dose led to reported disappearance of the toxicity. ${ }^{22}$ Prevalence (\%) was measured as a proportion relative to the total number of drug-receiving patients.

Data on study characteristics, methodological quality and results were independently extracted from each selected article using a pre-defined extraction form by two authors (TJH and SD). This form captured: author, study location, study design, observation period, number of patients treated, patient age, sex and reported race or ethnicity, drug resistance profile, prior treatment with second-line drugs, HIV status, treatment regimen with $\mathrm{Cfz}$, dosage, duration of treatment, treatment outcomes, reported ADRs by agent and rate of discontinuation. An additional author (DFW) independently assessed the validity of included citations and extracted data.

\section{Statistical analysis}

We calculated point estimates and $95 \%$ CIs for the frequency of adverse events and ADRs. We assessed the heterogeneity between studies using the $\mathrm{I}^{2}$ statistic, which reports the proportion of total variance across studies 
that is due to between-study heterogeneity rather than by randomness (see online supplementary appendix). Based on this assessment, we used the DerSimonian and Laird $^{23}$ random effects model for pooling estimates and calculating 95\% CI of adverse event frequencies, and the inverse-variance weighted fixed effects model for ADRs. ${ }^{24}$ Since some studies reported no ADRs, we also performed a post hoc sensitivity analysis to calculate 95\% CI of adverse events and ADRs using the Wilson score method and found that the intervals did not differ significantly. We defined statistical significance at the $\mathrm{p}<0.05$ level. Forest plots illustrate the distributions of pooling adverse event data by various stratification criteria. Statistical analyses were performed using Stata (V.12.0, Stata Corp).

\section{RESULTS}

Safety

From 1248 citations identified by our search strategy, 147 were selected for full-text review (figure 1). A total of five studies were subsequently included in the review for safety.

The characteristics of the five selected studies with safety data are summarised in table $1 .{ }^{16}{ }^{25-28}$ Of the total 861 participants, 602 patients received $\mathrm{Cfz}$ as part of their TB treatment regimens. The study periods ranged from 1993 to 2012. The average study population was 144 patients (range 10-427). The daily dose range of Cfz administered in clinical settings was $50-100 \mathrm{mg}$, though one study reported a daily dose of $300 \mathrm{mg} .{ }^{25}$ Drug resistance patterns, duration and extent of prior TB treatment, HIV status and types of ADRs were variably reported.

The two most reported adverse event categories were dermal (skin discolouration) and gastrointestinal. As

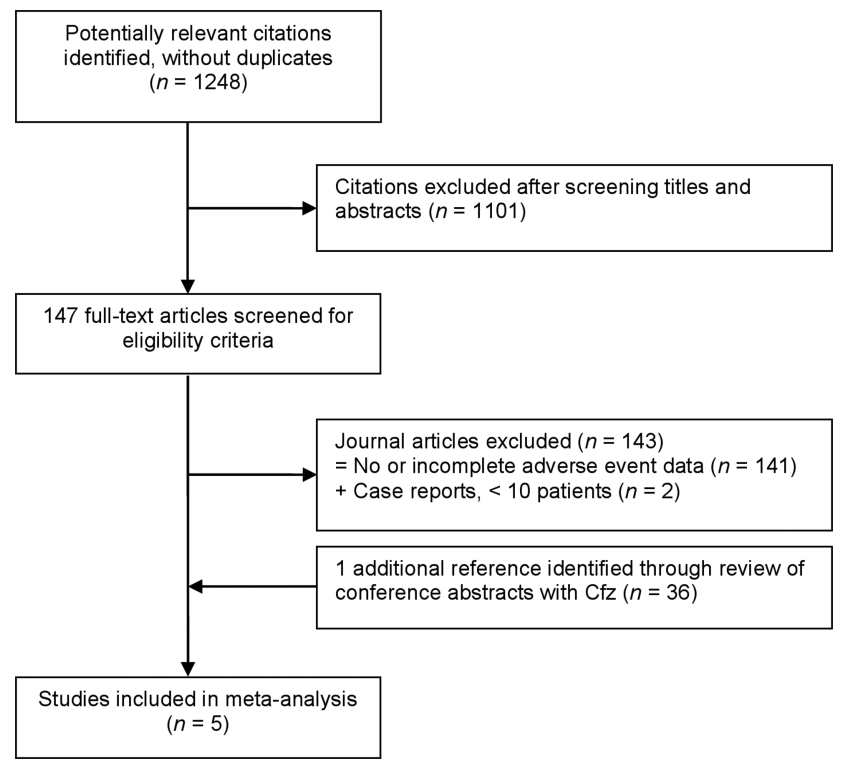

Figure 1 Study selection process for meta-analysis of safety of $\mathrm{Cfz}$ in treatment of TB. Cfz,clofazimine; TB, tuberculosis. shown in figure 2, the overall pooled proportion of all adverse events attributed to Cfz was $21.9 \%$ (95\% CI $(0.0 \%$ to $46.1 \%))$, though the median frequency of adverse events was $5 \cdot 1 \%$. The pooled proportion was disproportionately affected by an outlier reporting adverse events in $88.6 \%$ (95\% CI $(75.4 \%$ to $96.2 \%)$ ) of cases. ${ }^{27}$

Not all reported adverse events required discontinuation of Cfz treatment. From our fixed effects model, the pooled proportion of ADRs requiring discontinuation or withdrawal of $\mathrm{Cfz}$ was $0.1 \%$ (95\% CI $(0.0 \%$ to $0.6 \%)$ ), with the frequency of ADRs ranging from $0 \%$ $(95 \%$ CI $(0.0 \%$ to $1.1 \%))$ to $11.8 \%$ (95\% CI $(2.0 \%$ to $35.6 \%))$.

\section{Efficacy}

Early in vitro studies of $\mathrm{Cfz}$ reported positive bactericidal efficacy of Cfz. ${ }^{29-33}$ More recent in vitro and in vivo evidence suggests that $\mathrm{Cfz}$ also has sustained sterilising activity against latent or persistent bacterial populations of $M$ tuberculosis. ${ }^{34}$ Currently, novel analogues of Cfz are under investigation with comparable efficacy but shorter half-lives, potentially reducing tissue accumulation and resultant skin pigmentation. ${ }^{35}$

In vivo studies in mice and hamsters reported significant activity of $\mathrm{Cfz}$, though accumulation in animal tissues may lead to overestimation of drug activity when subsequently plated on solid media. ${ }^{12}{ }^{30}{ }^{36-38}$ Earlier studies had shown that Cfz had little or no activity in guinea pig and monkey models. ${ }^{15}{ }^{39}$ It was later thought that these poor in vivo results and monotherapy-induced resistance in guinea pigs and monkeys may have been a result of low absorption of the drug by the oral route. ${ }^{29}$ Recently, Cfz combined with bedaquiline and pyrazinamide has been shown to be superior to the current firstline regimen in reducing colony-forming unit counts at 1 month in mice. ${ }^{40} \mathrm{Cfz}$ combined with the standard second-line regimen also significantly improved culture conversion and relapse prevention, compared with a regimen without $\mathrm{Cfz}$, in mice. ${ }^{41} \mathrm{In}$ addition, the sterilising activity of bedaquiline and pyrazinamide was significantly improved with the addition of Cfz. ${ }^{42}$

\section{Effectiveness}

In a recent systematic review and meta-analysis of 3489 patients treated for drug-resistant TB across 10 countries, Dey $e t a t^{43}$ reported a pooled treatment success rate of $62.0 \%$ (95\% CI $(52.8 \%$ to $71.1 \%)$ ) from treatment regimens containing $\mathrm{Cfz}$, with success defined as cure and/ or treatment completion. The success rate in HIV/ MDR-TB coinfected patients was not significantly different from the overall success rate. In another systematic review of patients treated with Cfz-containing regimens, Gupta et al found no significant differences in the proportions with favourable outcomes between patients with MDR-TB $(65 \%$; $95 \%$ CI $(52 \%$ to $79 \%))$ and patients with XDR-TB $(66 \% ; 95 \%$ CI $(42 \%$ to $89 \%)) .{ }^{44}$ There was substantial variation in estimates of mortality during treatment with Cfz-containing regimens, ranging from 
Table 1 Characteristics of studies included in a systematic review of safety of clofazimine in the treatment of TB

\begin{tabular}{|c|c|c|c|c|c|c|c|c|}
\hline $\begin{array}{l}\text { Author, year, } \\
\text { reference }\end{array}$ & Country & $\begin{array}{l}\text { Study } \\
\text { period }\end{array}$ & $\begin{array}{l}\text { Study } \\
\text { design }\end{array}$ & $\begin{array}{l}\text { Study population } \mathrm{N} \\
\text { included participants }\end{array}$ & $\begin{array}{l}\text { Treatment } \\
\text { duration } \\
\text { (months) }\end{array}$ & Regimen & $\begin{array}{l}\text { N. given } \\
\text { Cfz }\end{array}$ & $\begin{array}{l}\text { Daily Cfz } \\
\text { dose (mg) }\end{array}$ \\
\hline Goble et al $(1993)^{25}$ & USA & $1973-1983$ & Retrospective & $\begin{array}{l}171 \text { patients included } \\
\text { Age: } 46(17-79) \\
\text { DS: 0; DR: } 98\end{array}$ & 7 & Individualised & 17 & 300 \\
\hline Geerligs et al $(2000)^{26}$ & Netherlands & 1985-1998 & Retrospective & $\begin{array}{l}44 \text { patients included } \\
\text { Age: } 33(10-82) \\
\text { DS: 0; DR: } 44\end{array}$ & $20-53$ & Individualised & 39 & Not stated \\
\hline Van Deun et al (2010) ${ }^{16}$ & Bangladesh & 1997-2007 & Prospective & $\begin{array}{l}427 \text { patients included } \\
\text { Age: } 33.8 \text { (mean) } \\
\text { DS: 0; DR: } 427\end{array}$ & $3-15$ & $\begin{array}{l}\text { Cfz, Km, Ofx, E, } \\
\text { H, Z, Pto }\end{array}$ & 427 & $50-100$ \\
\hline $\mathrm{Xu}$ et al $(2012)^{27}$ & $\begin{array}{l}\text { People's Republic } \\
\text { of China }\end{array}$ & 2006-2011 & Retrospective & $\begin{array}{l}144 \text { patients included } \\
\text { Age: } 38.8 \pm 10.8(\mathrm{Cfz}) \\
47.4 \pm 11.8 \text { (non-Cfz) } \\
\text { DS: } 0 \text {; DR: } 144\end{array}$ & $\begin{array}{l}2.2 \pm 1.7(\mathrm{Cfz}) \\
2.1 \pm 1.3(\mathrm{non}-\mathrm{Cfz})\end{array}$ & Individualised & 44 & 100 \\
\hline Piubello et al $(2012)^{28}$ & Niger & 2008-2010 & Retrospective & $\begin{array}{l}65 \text { patients included } \\
\text { Age: } 32.7(16-66) \\
\text { DS: } 0 ; \text { DR: } 65\end{array}$ & 12 & $\begin{array}{l}\text { Cfz, Km, Ga, E, } \\
\mathrm{H}, \mathrm{Z}, \text { Pto }\end{array}$ & 65 & $50-100$ \\
\hline
\end{tabular}

Cfz, clofazimine; E, ethambutol; DR, drug-resistant (to at least two agents in standard-line therapy); DS, drug-sensitive; Ga, gatifloxacin; H, isoniazid; Km, kanamycin; Ofx, Ofxofloxacin; Pto,

prothionamide; S, streptomycin; TB, tuberculosis; Z, pyrazinamide. 


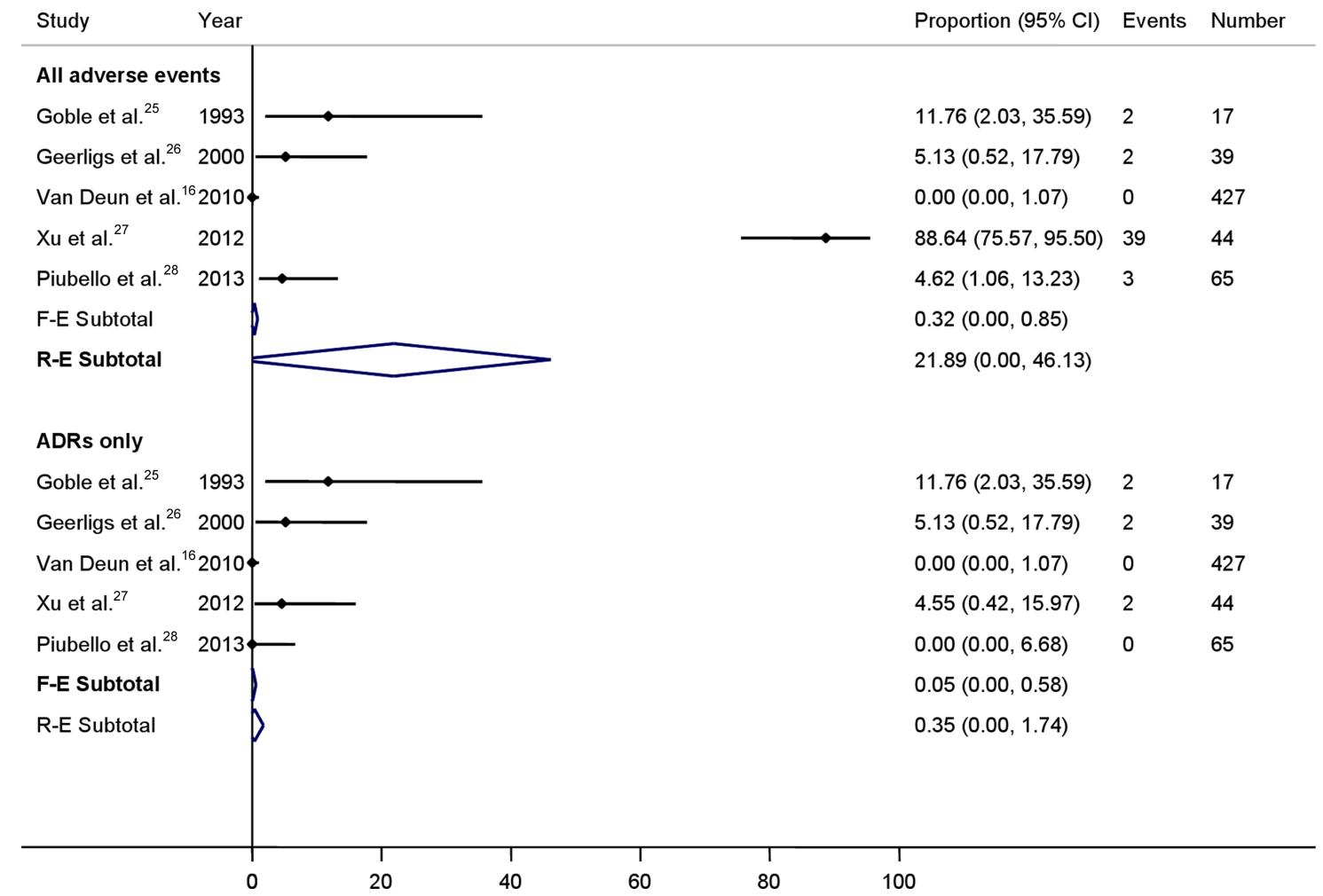

Figure 2 Forest plot of all reported adverse events associated with or ADRs attributed to clofazimine and clofazimine-containing regimens, pooled estimates using inverse-variance weighted fixed effects and random effects models are shown. The random effects model was used for adverse events estimates $\left(I^{2}=98.7 \% ; p<0.001\right)$ and fixed effects for $A D R s\left(I^{2}=11.5 \% ; p=0.34\right)$. ADRs, adverse drug reactions; FE, fixed effects; RE, random effects.

$1.0 \%(95 \%$ CI $0.1 \%$ to $2.6 \%)$ to $63.4 \%$ (95\% CI $38.3 \%$ to $85.0 \%)$, though the risk of death attributed solely to Cfz, after adjusting for covariates, was not reported. Further cohort studies showing a favourable effect of Cfz-containing regimens have been reported in Benin, ${ }^{45}$ South Africa ${ }^{46}$ and Ukraine, ${ }^{47}$ though limited benefit from $\mathrm{Cfz}$ was found in studies in Brazil ${ }^{48}$ and Sri Lanka. ${ }^{49}$
Two clinical trials are currently ongoing involving the investigation of the efficacy and safety of treatment regimens containing Cfz (table 2). The Global Alliance for TB Drug Development is conducting a Phase 2 study to evaluate the early bactericidal activity of $\mathrm{Cfz}$ (dosed at $300 \mathrm{mg}$ for the first 2 days and $100 \mathrm{mg}$ thereafter) combined with bedaquiline and pyrazinamide, compared with first-line treatment. ${ }^{50}$ The Phase 3 STREAM trial,

\begin{tabular}{|c|c|c|c|c|c|c|}
\hline Phase & Date & $\begin{array}{l}\text { Trial name } \\
\text { (identifier) }\end{array}$ & Sponsor & Design & $\begin{array}{l}\text { Treatment arms } \\
\text { (Cfz daily dose) }\end{array}$ & Primary endpoint \\
\hline $\begin{array}{l}\text { Phase } \\
\text { III }\end{array}$ & $2011-2016$ & $\begin{array}{l}\text { STREAM } \\
(\text { ISRCTN78372190) })^{17}\end{array}$ & $\begin{array}{l}\text { International } \\
\text { Union Against } \\
\text { Tuberculosis } \\
\text { and Lung } \\
\text { Disease }\end{array}$ & Non-inferiority & $\begin{array}{l}\text { Bangladesh regimen }{ }^{16} \\
\text { vs locally used WHO } \\
\text { MDR-TB regimen } \\
(\mathrm{Cfz}=50-100 \mathrm{mg})\end{array}$ & $\begin{array}{l}\text { Proportion of } \\
\text { patients with a } \\
\text { favourable } \\
\text { outcome (cure or } \\
\text { completion) } \\
27 \text { months after } \\
\text { randomisation }\end{array}$ \\
\hline $\begin{array}{l}\text { Phase } \\
\text { II }\end{array}$ & 2012-2013 & $\begin{array}{l}\text { NC-003 } \\
(\text { NCT01691534) }\end{array}$ & $\begin{array}{l}\text { Global Alliance } \\
\text { for TB Drug } \\
\text { Development }\end{array}$ & Superiority & $\begin{array}{l}\text { Bedaquiline (J), } \\
\text { PA-824 (PA), Z, Cfz } \\
\text { vs. J-PA-Z vs. } \\
\text { J-PA-Cfz vs. J-Z-Cfz } \\
\text { vs. Z alone vs. Cfz } \\
\text { alone vs. Rifafour } \\
\text { (Cfz=100-300 mg) }\end{array}$ & $\begin{array}{l}\text { Early bactericidal } \\
\text { activity (rate of } \\
\text { change of log } \\
\text { CFU per mL } \\
\text { sputum) }\end{array}$ \\
\hline
\end{tabular}


sponsored by the International Union Against Tuberculosis and Lung Disease, is comparing a modified MDR-TB treatment regimen, based on the shorter treatment regimens assessed in Bangladesh, ${ }^{16}$ with regimens based on the current WHO guidelines for MDR-TB treatment. The STREAM trial involves sites in Ethiopia, India, South Africa and Vietnam. ${ }^{17}$ Follow-up is expected for all patients in the study for 27-33 months, with final results anticipated after October 2016.

\section{Availability, cost and demand forecast}

Cfz was registered under the trade name Lamprene by Novartis in the USA in $1986 .{ }^{51}$ Quality-assured Cfz is available on very limited quantities for the treatment of patients with MDR-TB on a patient-named basis through the Global Drug Facility (GDF) mechanism of the Stop TB Partnership, which uses a distributor authorised by Novartis. ${ }^{52-54}$ Securing a steady supply of quality-assured Cfz that can meet the increasing demand for MDR-TB treatment, without jeopardising the needs of the global programme for leprosy elimination, is currently a major challenge in the response to MDR-TB. ${ }^{55}$

The price of the $100 \mathrm{mg}$ product through the GDF mechanism is US $\$ 120.86 / 100$ capsules, or roughly US $\$ 1.21$ per capsule. The cost of a daily dosage of Cfz varies between US $\$ 1.21$ (when a $100 \mathrm{mg}$ dosage is used) and US\$3.63 (when $300 \mathrm{mg}$ is used). Depending on the regimen and dosage, the cost of Cfz can be higher than the cost of a daily dosage of most injectables used in the treatment of intensive phase of MDR-TB treatment. By our calculations, the estimated annual cost of procuring a 24-month-regimen of Cfz will range between US\$2-20 million, depending on the number of patients (low estimate: patients with XDR-TB only; high estimate: all patients with MDR-TB) treated.

\section{Global policy, guidelines and national practices}

From a search of the national, regional and international guidelines and regulations relating to the use of Cfz, two policy sources were retrieved from the $\mathrm{WHO}^{56-59}$ and the US FDA (table 3$)^{60}$

Cfz is currently indicated solely for leprosy by the WHO and the US FDA, and is included in the WHO Model Lists of Essential Medicines for adults and children. ${ }^{61}{ }^{62}$ For this use, the drug is provided free to endemic countries through an agreement with the sole manufacturer of quality-assured Cfz, Novartis, first signed in 1999 and renewed in $2010 .^{63}$ The most recent donation, valued at US\$26 million, will treat an estimated 1.1 million patients with leprosy over 5 years (2010-2015). In the USA, Cfz can only be obtained through the National Hansen's Disease Programme under a single-patient treatment investigational new drug protocol administered by the US FDA. ${ }^{64}$

WHO guidelines currently do not recommend the routine use of $\mathrm{Cfz}$ for the treatment of DR-TB, due to insufficient data supporting the drug's efficacy and longterm safety. ${ }^{56}{ }^{57} \mathrm{~A}$ WHO consultation in early 2012 on diagnostic definition and treatment options for so-called 'totally drug-resistant TB' concluded, based on expert opinion, that Cfz (at a daily dose of $100 \mathrm{mg}$ ) and linezolid were likely to be the most effective in the group 5

Table 3 Guidelines and labelling regulations for $\mathrm{Cfz}$

\begin{tabular}{|c|c|c|c|c|c|}
\hline Authority & Region & Indication & Adverse effects & Off-label use & $\begin{array}{l}\text { Recommendation for } \\
\text { Cfz in TB use }\end{array}$ \\
\hline $\mathrm{WHO} 5657$ & Global & MDR-TB and XDR-TB & $\begin{array}{l}\text { Gastrointestinal } \\
\text { intolerance }\end{array}$ & $\begin{array}{l}\text { Named patient } \\
\text { basis on } \\
\text { 'exceptional' } \\
\text { grounds }\end{array}$ & $\begin{array}{l}\text { 2011: 'May be used but } \\
\text { not included among } \\
\text { drugs making up the } \\
\text { standard regimen' 2008: } \\
\text { 'Only if additional drugs } \\
\text { are needed to bring the } \\
\text { total to four' }\end{array}$ \\
\hline $\mathrm{WHO}^{5859}$ & Global & $\begin{array}{l}\text { Leprosy and severe } \\
\text { ENL reactions in } \\
\text { leprosy }\end{array}$ & $\begin{array}{l}\text { Discolouration, } \\
\text { ichthyosis }\end{array}$ & $\begin{array}{l}\text { Named patient } \\
\text { basis on } \\
\text { 'exceptional' } \\
\text { grounds }\end{array}$ & $\begin{array}{l}\text { m...In the treatment of } \\
\text { multidrug resistant } \\
\text { tuberculosis (MDR TB)... } \\
\text { WHO has found no } \\
\text { evidence of its } \\
\text { effectiveness for these } \\
\text { forms of treatment }{ }^{58}\end{array}$ \\
\hline $\begin{array}{l}\text { Food and Drug } \\
\text { Administration }^{60}\end{array}$ & USA & $\begin{array}{l}\text { Lepromatous leprosy, } \\
\text { including } \\
\text { dapsone-resistant } \\
\text { lepromatous leprosy } \\
\text { and lepromatous } \\
\text { leprosy complicated by } \\
\text { ENL }\end{array}$ & $\begin{array}{l}\text { Skin pigmentation, } \\
\text { gastrointestinal, } \\
\text { conjunctival and } \\
\text { corneal pigmentation, } \\
\text { discolouration of } \\
\text { urine, faeces, sputum } \\
\text { and sweat }\end{array}$ & $\begin{array}{l}\text { Single-patient } \\
\text { treatment } \\
\text { investigational } \\
\text { new drug } \\
\text { protocol }\end{array}$ & Not stated \\
\hline
\end{tabular}


category of second-line anti-TB drugs for the treatment of XDR-TB. ${ }^{65}$

Seven articles were identified from the literature on the national policies, guidelines and practices on the use of $\mathrm{Cfz}$ to treat MDR-TB. ${ }^{66-72}$ There has been virtually no published evidence of the use of Cfz in the Russian Federation. The two articles retrieved from the Russian-language literature mention solely that $\mathrm{Cfz}$ is included in international guidelines as a third-line therapy but note that the drug is not currently registered in the country. ${ }^{66}{ }^{67} \mathrm{Cfz}$ was previously registered with the Russian Ministry of Health for the indication of leprosy in 1977 and reregistered in 1989. In 1995, Cfz's registration was annulled for unknown reasons and was not identifiable through the State Registry of Medical Substances as of May 2013. ${ }^{73}$

In India, use of $\mathrm{Cfz}$ has been associated with varying degrees of success in a number of settings, including in TB cases with strains described as so-called 'totally drug-resistant,${ }^{68}$ A survey of the clinical practices in the management of DR-TB cases by chest physicians in the Indian state of Maharashtra found that Cfz was a preferred drug, being included in the treatment regimens by 15 respondents of the 29 surveyed. ${ }^{69}$ A number of studies have reported the use of aggressive supervised therapies, including $\mathrm{Cfz}$ and other group 5 drugs such as linezolid and clarithromycin. ${ }^{70}{ }^{71}$ In one such study with 14 patients with XDR-TB, only two cases achieved complete cure (defined to be at least five negative culture results for the final 12 months of treatment), compared with four deaths. ${ }^{72}$

\section{DISCUSSION}

While data were limited, this study has shown a low proportion of adverse events requiring discontinuation of treatment attributed to $\mathrm{Cfz}$ at doses ranging from $50 \mathrm{mg}$ to $300 \mathrm{mg}$ daily. Our pooled frequency of Cfz ADRs at $0.1 \%$ is comparable to the incidence of serious ADRs reported with first-line TB treatment. ${ }^{74}$

These findings are in line with those made in an unpublished report on spontaneous individual case safety reports (ICSRs) submitted between 1976 and 2012 to the WHO's International Drug Monitoring Programme, which found that Cfz was associated with 288 ICSRs accounting for 674 ADRs (Wang $\mathbf{S}$ et al, unpublished data). The three most frequent systemic categories involved in the TB-specific ADRs were central and peripheral nervous system (23.2\%), gastrointestinal (17.9\%) and skin (16.1\%).

Our review of preclinical studies of Cfz suggests that this drug has sterilising activity against $M t b$. Observational cohort studies in Bangladesh, Benin, China, Niger, Peru and Sri Lanka, among other settings, show an association between treatment regimens containing $\mathrm{Cfz}$ and favourable outcomes, including shortened treatment duration and add support to its inclusion by WHO in the group 5 of drugs to be considered in the management of MDR-TB. ${ }^{57}$ A high variance in mortality rates of patients receiving Cfz-containing drug combinations is observed in some studies. While these data might be confounded by indication-as patients who receive Cfz-containing regimens tend to be those with broader-spectrum drug resistance patterns and more advanced disease- the increasing use of Cfz should be coupled with strengthening of active pharmacovigilance systems. ${ }^{22}$ Results from the Phase 3 STREAM and Phase 2 Global TB Alliance trials will help to elucidate further the long-term safety and effectiveness of Cfz in the treatment of MDR-TB.

Our analysis is limited by the small number of available studies and published materials on Cfz. As ADRs are often rare, the paucity of clinical investigations with Cfz in the treatment of TB means that our results should be interpreted with some caution. While we attempted to categorise ADRs based on resolution after withdrawal or recurrence with rechallenge, reporting varied across studies and different thresholds may have been applied to report adverse events and ADRs. In the Xu et $^{2 l^{27}}$ study, for instance, 39 of $44(87 \%)$ patients were reported to have experienced adverse events after starting Cfz. This high level of adverse events could be attributed to the high frequency of reported skin discolouration (36 patients), a known reaction to Cfz treatment, but only two patients discontinued Cfz altogether. There were also insufficient data on the extent of prior treatment, drug susceptibility and HIV status-factors that could result in varying severity of disease. Another limitation was that we considered participants in our meta-analysis as those with at least one $\mathrm{ADR}$ while being treated with $\mathrm{Cfz}$, rather than cumulatively counting multiple ADRs that may have been experienced. In addition, to review the global landscape of policies and regulatory actions relating to $\mathrm{Cfz}$, we relied on databases, search engines and manual searches which are biased in favour of English-language publications. Many more national and local policies may exist that were not captured in this article.

The use of Cfz in the clinical settings where patients with MDR-TB are treated has been increasing over the past two decades. The progress countries are making towards universal access to diagnosis and treatment of MDR-TB ${ }^{75}$ is resulting in sustained and increasing demand for this product, at least until more new and effective drugs are available. The GDF's projected forecast based on the ongoing global scale-up of MDR-TB management suggests that the current quality-assured supply line is insufficient to meet this demand. GDF and the Global Fund regularly publish joint invitations to manufacturers of first, second and third-line antituberculosis medicines to submit an Expression of Interest for TB drug products evaluation by the Expert Review Panel. However, to date, no successful review of Cfz has been reported through this mechanism. To improve access to the drug, generic manufacturers that can complement Novartis' production capacity should be identified. The inclusion of more manufacturers in the market may also contribute to a reduction in the cost of the drug, further improving access.

Despite these limitations, this article underscores the potential value of Cfz's inclusion in the treatment 
regimens for MDR-TB and XDR-TB cases. However, even if the ongoing clinical trials and observational studies confirm the earlier findings reviewed here, much more will need to be carried out to make Cfz available and affordable.

\section{Author affiliations}

${ }^{1}$ Faculty of Arts and Sciences, Harvard University, Cambridge, USA

${ }^{2}$ Program on Regulation, Therapeutics, and Law, Division of

Pharmacoepidemiology and Pharmacoeconomics, Department of Medicine, Brigham and Women's Hospital, Boston, USA

${ }^{3}$ Global TB Programme, World Health Organisation, Geneva, Switzerland

${ }^{4}$ Global Drug Facility, Stop TB Partnership and World Health Organisation, Geneva, Switzerland

${ }^{5}$ Global Infectious Disease Consulting, London, UK

${ }^{6}$ Program in Infectious Disease and Social Change, Department of Global Health and Social Medicine, Harvard Medical School, Boston, USA

Acknowledgements The authors thank Shu-Hua Wang for helping with data from the WHO's International Drug Monitoring Programme. The authors also thank the editor and the two reviewers at the journal for their review of the manuscript.

Contributors AJ, DFW, PN, SK and TJH had the idea for and designed the study. TJH and SD undertook data collection, and DFW supervised extraction and analysis. TJH analysed the data and developed drafts of the manuscript. AJ, DF, DFW, EJ, KL, KW, PN and SK contributed to interpretation of the results, drafting of the article and revisions of the manuscript. All authors contributed to and approved the final draft for publication.

Funding This research received no specific grant from any funding agency in the public, commercial or not-for-profit sectors.

Competing interests TJH and SD were supported by fellowships from the Harvard Kennedy School Institute of Politics. TJH also received a research grant for this study from the Dunwalke Fund at Harvard University SK has received partial salary support through a grant from the Eli Lilly Foundation's MDR-TB Partnership to Brigham and Women's Hospital. DF, DFW, EJ, KL and $\mathrm{KW}$ are staff members of WHO. The authors alone are responsible for the views expressed in this publication and they do not necessarily represent the decisions or policies of WHO.

Provenance and peer review Not commissioned; externally peer reviewed.

Data sharing statement The dataset is available from the corresponding author.

Open Access This is an Open Access article distributed in accordance with the Creative Commons Attribution Non Commercial (CC BY-NC 3.0) license, which permits others to distribute, remix, adapt, build upon this work noncommercially, and license their derivative works on different terms, provided the original work is properly cited and the use is non-commercial. See: http:// creativecommons.org/licenses/by-nc/3.0/

\section{REFERENCES}

1. Satti $\mathrm{H}$, McLaughlin MM, Seung KJ, et al. High risk of drug-resistant tuberculosis when first-line therapy fails in a high HIV prevalence setting. Int J Tuberc Lung Dis 2013;17:100-6.

2. World Health Organization (WHO). Global tuberculosis report 2012. WHO/HTM/TB/2012.6. Geneva, Switzerland: WHO, 2012.

3. WHO. Towards universal access to diagnosis and treatment of multidrug-resistant and extensively drug-resistant tuberculosis by 2015: WHO progress report 2011. WHO/HTM/TB/2011.3. Geneva Switzerland: WHO, 2011

4. Skrahina A, Hurevich $\mathrm{H}$, Zalutskaya $A$, et al. Alarming levels of drug-resistant tuberculosis in Belarus: results of a survey in Minsk. Eur Respir J 2012;39:1425-31.

5. US Food and Drug Administration (US FDA). Press release: approval of Sirturo (bedaquiline). FDA, 2012.

6. Otsuka Pharmaceutical Co., Ltd. News release: Otsuka's Novel treatment for multidrug-resistant tuberculosis, delamanid, submitted for regulatory approval. Otsuka, 2013.
7. Caminero JA, Sotgiu G, Zumla A, et al. Best drug treatment for multidrug-resistant and extensively drug-resistant tuberculosis. Lancet Infect Dis 2010;10:621-9.

8. Dooley KE, Mitnick CD, Ann DeGroote M, et al. Efficacy Subgroup, RESIST-TB. Old drugs, new purpose: retooling existing drugs for optimized treatment of resistant tuberculosis. Clin Infect Dis 2012;55:572-81.

9. Barry VC, Belton JG, Conalty M, et al. A new series of phenazines (rimino-compounds) with high antituberculosis activity. Nature 1957;179:1013-15.

10. Dooley KE, Obuku EA, Durakovic N, et al. on behalf of the Efficacy Subgroup, RESIST-TB. World Health Organization Group 5 Drugs for the Treatment of Drug-Resistant Tuberculosis: unclear efficacy or untapped potential? J Infect Dis 2013;207:1352-8.

11. Cholo MC, Steel HC, Fourie PB, et al. Clofazimine: current status and future prospects. J Antimicrob Chemother 2012;67:290-8.

12. Reddy VM, O'Sullivan JF, Gangadharam PR. Antimycobacterial activities of riminophenazines. J Antimicrob Chemother 1999;43:615-23.

13. Fajardo TT, Abalos RM, dela Cruz EC, et al. Clofazimine therapy for lepromatous leprosy: a historical perspective. Int J Dermatol 1999;38:70-4

14. Barry VC, Buggie K, Byrne J, et al. Absorption, distribution and retention of the imino compounds in the experimental animals. Ir $J$ Med Sci 1960;416:345-52.

15. Schmidt LH, Hoffman R, Jolly PN. Induced pulmonary tuberculosis in the rhesus monkey: its usefulness in evaluating chemotherapeutic agents. Proceedings of 14th Conference V. A.-A.F. Tuberculosis (Veteran Administration: Army: Navy). 1955:266-31.

16. Van Deun A, Maug AK, Salim MA, et al. Short, highly effective, and inexpensive standardized treatment of multidrug-resistant tuberculosis. Am J Respir Crit Care Med 2010;182:684-92.

17. Current Controlled Trials. The evaluation of a standardised treatment regimen of anti-tuberculosis drugs for patients with multi-drug-resistant tuberculosis (STREAM). ISRCTN 2011; Identifier: ISRCTN78372190. http://www.controlled-trials.com/ ISRCTN78372190/STREAM

18. Stroup DF, Berlin JA, Morton SC, et al. for the Meta-analysis Of Observational Studies in Epidemiology (MOOSE) Group. Meta-analysis of observational studies in epidemiology: a proposal for reporting. JAMA 2000;283:2008-12.

19. Moher D, Liberati A, Tetzlaff J, et al. PRISMA Group. Preferred reporting items for systematic reviews and meta-analyses: the PRISMA statement. PLoS Med 2009;6:e1000097.

20. Edwards IR, Aronson JK. Adverse drug reactions: definitions, diagnosis, and management. Lancet 2000;356:1255-9.

21. Hwang TJ, Wares DF, Jafarov A, et al. Safety of cycloserine and terizidone for the treatment of drug-resistant tuberculosis: a meta-analysis. Int J Tuberc Lung Dis 2013;17:1257-66.

22. WHO. A practical handbook on the pharmacovigilance of medicines used in the treatment of tuberculosis: enhancing the safety of the TB patient. Geneva, Switzerland: WHO, 2012.

23. DerSimonian R, Laird N. Meta-analysis in clinical trials. Control Clin Trials 1986;7:177-88.

24. Higgins JP, Thompson SG, Deeks JJ, et al. Measuring inconsistency in meta-analyses. BMJ 2003:327:557-60.

25. Goble M, Iseman MD, Madsen LA, et al. Treatment of 171 patients with pulmonary tuberculosis resistant to isoniazid and rifampin. N Engl J Med 1993;328:527-32.

26. Geerligs WA, Van Altena R, De Lange WCM, et al. Multidrug-resistant tuberculosis: long-term treatment outcome in the Netherlands. Int J Tuberc Lung Dis 2000;4:758-64.

27. Xu HB, Jiang RH, Tang SJ, et al. Role of clofazimine in the treatment of multidrug-resistant tuberculosis: a retrospective observational cohort assessment. J Antimicrob Chemother 2013 In Press. doi:10.1093/jac/dks077.

28. Piubello A, Hassane Harouna S, Boukary I, et al. High rate of cure and no relapse of short standardized treatment of multidrug resistant tuberculosis in Niger. In: The 43rd World Congress on Lung Health of the International Union against Tuberculosis and Lung Disease (The Union). Kuala Lumpur, Malaysia, 2012:S179.

29. Reddy VM, Nadadhur G, Daneluzzi D, et al. Antituberculosis activities of clofazimine and its new analogs B4154 and B4157. Antimicrob Agents Chemother 1996;40:633-6.

30. Jagannath C, Reddy MV, Kailasam S, et al. Chemotherapeutic activity of clofazimine and its analogues against Mycobacterium tuberculosis: in vitro, intracellular, and in vivo studies. Am J Respir Crit Care Med 1995;151:1083-6.

31. Rastogi N, Goh KS, Bryskier A, et al. In vitro activities of levofloxacin used alone and in combination with first- and second-line 
antituberculous drugs against Mycobacterium tuberculosis. Antimicrob Agents Chemother 1996;40:1610-16.

32. Rastogi N, Goh KS, Horgen L, et al. Synergistic activities of antituberculous drugs with cerulenin and trans-cinnamic acid against Mycobacterium tuberculosis. FEMS Immunol Med Microbiol 1998;21:149-57.

33. De Logu A, Onnis V, Saddi B, et al. Activity of a new class of isonicotinoylhydrazones used alone and in combination with isoniazid, rifampicin, ethambutol, para-aminosalicylic acid and clofazimine against Mycobacterium tuberculosis. J Antimicrob Chemother 2002;49:275-82.

34. $\mathrm{Xu} \mathrm{J}, \mathrm{Lu} Y, \mathrm{Fu} \mathrm{L}$, et al. In vitro and in vivo activity of clofazimine against Mycobacterium tuberculosis persisters. Int $J$ Tuberc Lung Dis 2012;16:1119-25.

35. Lu Y, Zheng M, Wang B, et al. Clofazimine analogs with efficacy against experimental tuberculosis and reduced potential for accumulation. Antimicrob Agents Chemother 2011:55:5185-93.

36. Adams LB, Sinha I, Franzblau SG, et al. Effective treatment of acute and chronic murine tuberculosis with liposome-encapsulated clofazimine. Antimicrob Agents Chemother 1999;43:1638-43.

37. Barry VC, Conalty ML. Antituberculosis activity in the phenazine series. Am Rev Tuberc 1958;78:62-73.

38. Vischer WA. The experimental properties of G30320 (B663)-a new antileprotic agent. Leprosy Rev 1969;40:107-10.

39. Steenken $\mathrm{W} \mathrm{Jr}$, Montalbine $\mathrm{V}$, Smith MM. Antituberculous activity of rimino compound of the phenazine series. Am Rev Respir Dis 1960;81:764-7.

40. Tasneen R, Li SY, Peloquin CA, et al. Sterilizing activity of novel TMC207- and PA-824-containing regimens in a murine model of tuberculosis. Antimicrob Agents Chemother 2011;55:5485-92.

41. Grosset JH, Tyagi S, Almeida DV, et al. Assessment of clofazimine activity in a second-line regimen for tuberculosis in mice. $A m \mathrm{~J}$ Respir Crit Care Med 2013;188:608-12.

42. Williams K, Minkowski A, Amoabeng $\mathrm{O}$, et al. Sterilizing activities of novel combinations lacking first- and second-line drugs in a murine model of tuberculosis. Antimicrob Agents Chemother 2012;56:3114-20.

43. Dey T, Brigden $\mathrm{G}, \mathrm{Cox} \mathrm{H}$, et al. Outcomes of clofazimine for the treatment of drug-resistant tuberculosis: a systematic review and meta-analysis. J Antimicrob Chemother 2013;68:284-93.

44. Gopal M, Padayatchi N, Metcalfe JZ, et al. Systematic review of clofazimine for the treatment of drug-resistant tuberculosis. Int $J$ Tuberc Lung Dis 2013;17:1001-7.

45. Kassa F, Affolabi D, Ade G, et al Successful 12-month treatment for multidrug-resistant tuberculosis patients in Benin. In: The 43rd World Congress on Lung Health of the International Union Against Tuberculosis and Lung Disease (The Union), Kuala Lumpur, Malaysia, 2012:S310

46. Gopal M, Naidoo R, O'Donnell M, et al. A retrospective cohort study of clofazimine in the treatment of extensively drug-resistant tuberculosis in South Africa. In: The 43rd World Congress on Lung Health of the International Union Against Tuberculosis and Lung Disease (The Union). Kuala Lumpur, Malaysia, 2012:S214.

47. Lyepshina S, Serduk O, Tyshchenko H. Treatment results of clofazimine used in the management of multidrug-resistant tuberculosis patients during the intensive phase of treatment. In: The 43rd World Congress on Lung Health of the International Union Against Tuberculosis and Lung Disease (The Union). Kuala Lumpur, Malaysia, 2012:S216

48. Braga JU, Bastos LGV, Rocha JL, et al. Effectiveness of a therapeutic regimen using clofazimine for MDR-TB treatment in Brazil. In: The 42nd World Congress on Lung Health of the International Union Against Tuberculosis and Lung Disease (The Union). Lille, France, 2011:S320.

49. Senaratne WV. Outcome of treatment of multidrug resistant tuberculosis. Ceylon Med J 2004;49:86-7.

50. Evaluation of early bactericidal activity in pulmonary tuberculosis with clofazimine (C)-TMC207 (J)-PA-824 (Pa)-pyrazinamide (Z) (NC-003). Identifier: NCT01691534. http://clinicaltrials.gov/ct2/show/ NCT01691534
51. US FDA. Orange book: clofazimine (Lamprene). FDA, 2013.

52. Green Light Committee Initiative. Annual Report 2008. Geneva, Switzerland: WHO/STP, 2009.

53. WHO. Multidrug therapy (MDT): use of clofazimine for treating ENL reactions in leprosy [Online]. Geneva, Switzerland: WHO. http:// www.who.int/lep/mdt/clofazimine/en/index.htm

54. Medecins Sans Frontières. DR-TB drugs under the microscope: sources and prices for drug-resistant tuberculosis medicines, 2nd edn. MSF, 2012.

55. WHO. Global Green Light Committee meeting report. Geneva, Switzerland: WHO, 2012. http://www.who.int/tb/challenges/mdr/ greenlightcommittee/Meetingreport2ndgGLCmeeting.pdf

56. WHO. Guidelines for the programmatic management of drug-resistant tuberculosis. WHO/HTM/TB 2008.402. Geneva, Switzerland: WHO, 2008

57. WHO. Guidelines for the programmatic management of drug-resistant tuberculosis-2011 update. WHO/HTM/TB 2011.6. Geneva, Switzerland: WHO, 2011

58. WHO. Guidelines for the management of severe erythema nodosum leprosum (ENL) reactions. Geneva, Switzerland: WHO. http://www. who.int/lep/research/WHOenlguide.pdf

59. WHO. Guide to eliminate leprosy as a public health problem. WHO/ CDS/CPE/CEE/2000.14. Geneva, Switzerland: WHO, 2000.

60. US FDA. Label and prescribing information: Lamprene $\AA$ (Novartis). FDA, 1998.

61. WHO. WHO model list of essential medicines. 17th edn. Geneva, Switzerland: WHO, 2011.

62. WHO. WHO model list of essential medicines for children. 3rd edn Geneva, Switzerland: WHO, 2011.

63. WHO. New memorandum of understanding for MDT. Geneva, Switzerland: WHO, 2010.

64. Worobec SM. Current approaches and future directions in the treatment of leprosy. Res Rep Trop Med 2012;3: 79-91.

65. WHO. 'Totally Drug-Resistant TB': a WHO consultation on the diagnostic definition and treatment options. Geneva, Switzerland: WHO, 2012

66. Borisov GB, Sokolova . Etiotropnoe lechenie tuberkuleza pri lekarstvennoj ustojchivosti M tuberculosis: vzglyady I rekomendatsi mezhdunarodnyh organizatsij. Consilium Medicum 2001; 3:12.

67. Chukanov VI. Problema izlecheniya bolnyh tuberkulezom organov dynahiya. Central Scientific Research Institute of Tuberculosis of Russian Academy of Sciences, 954.

68. Udwadia Z, Vendoti D. Totally drug-resistant tuberculosis (TDR-TB) in India: every dark cloud has a silver lining. J Epidemiol Community Health 2013;67:471-2.

69. Udwadia ZF, Amale RA, Ajbani KK, et al. Totally drug-resistant tuberculosis in India. Clin Infect Dis 2012;54:579-81.

70. Dutta NK, Karakousis PC. Tuberculosis chemotherapy: present situation, possible solutions, and progress towards a TB-free world Indian J Med Microbiol 2012;30:261-3.

71. Prasad M, Shashirekha K, Bhattacharyya D, et al. Extensively drug-resistant (XDR) pulmonary tuberculosis in HIV negative cases. The ERS Annual Congress (Session 252-The Challenge of Multidrug-Resistant Tuberculosis). Berlin, Germany, 2008:441s.

72. Prasad M, Rai S, Falleiro J, et al. Prevalence and treatment outcome of drug resistant pulmonary tuberculosis in HIV negative cases-experience from a tuberculosis treatment center in India. The ERS Annual Congress (Session 400-Multi/Extensively-drug resistant tuberculosis). Vienna, Austria, 2009:4447.

73. Russian State Registry of Medical Substances. Lamprene (Лампрен). http://grls.rosminzdrav.ru/

74. Yee D, Valiquette C, Pelletier M, et al. Incidence of serious side effects from first-line antituberculosis drugs among patients treated for active tuberculosis. Am J Respir Crit Care Med 2003;167:1472-7.

75. Falzon D, Jaramillo $E$, Wares $F$, et al. Universal access to care for multidrug-resistant tuberculosis: an analysis of surveillance data. Lancet Infect Dis 2013:13:690-7. 